Article

\title{
Adsorptive Removal of Reactive Black 5 from Wastewater Using Bentonite Clay: Isotherms, Kinetics and Thermodynamics
}

\author{
Muhammad Tahir Amin *, Abdulrahman Ali Alazba and Muhammad Shafiq \\ Alamoudi Water Research Chair, King Saud University, P.O. Box 2460, Riyadh 11451, Saudi Arabia; \\ E-Mails: alazba@ksu.edu.sa (A.A.A.); msrana.c@ksu.edu.sa (M.S.) \\ * Author to whom correspondence should be addressed; E-Mail: mtamin@ksu.edu.sa; \\ Tel.: +966-114673737; Fax: +966-114673739.
}

Academic Editor: Vincenzo Torretta

Received: 16 September 2015 / Accepted: 13 November 2015 / Published: 18 November 2015

\begin{abstract}
The studies of the kinetics and isotherms adsorption of the Reactive Black 5 (RB5) onto bentonite clay were explored in a batch study in a laboratory. The maximum RB5 adsorption conditions of bentonite clay were optimized such as shaking speed (100 rpm), temperature (323 K), pH (10), contact time (40 min), initial dye concentration $\left(170 \mathrm{mg} \cdot \mathrm{L}^{-1}\right)$, and particle size $(177 \mu \mathrm{m})$. The adsorbent surface was characterized using Fourier Transform Infrared Spectroscopy spectroscopy. The mechanisms and characteristic parameters of the adsorption process were analyzed using two parameter isotherm models which revealed the following order (based on the coefficient of determination): Harkin-Jura $(0.9989)>$ Freundlich (0.9986) and Halsey (0.9986) > Langmuir (0.9915) > Temkin (0.9818) $>$ Dubinin-Radushkevich (0.9678). This result suggests the heterogeneous nature of bentonite clay. Moreover, the adsorption process was chemisorption in nature because it follows the pseudo-second order reaction model with $R^{2}$ value of $0.9998,0.9933$ and 0.9891 at 25,75 and $100 \mathrm{mg} \cdot \mathrm{L}^{-1} \mathrm{RB} 5$ dye in the solution, respectively. Moreover, based on the values of standard enthalpy, Gibbs free energy change, and entropy, bentonite clay showed dual nature of exothermic and endothermic, spontaneous and non-spontaneous as well as increased and decreased randomness at solid-liquid interface at 303-313 $\mathrm{K}$ and 313-323 K temperature, respectively.
\end{abstract}

Keywords: bentonite clay; isotherms; kinetics; textile dye; Thermodynamics 


\section{Introduction}

Color is an important part of the human world. A few decades earlier, the selection, application and use of dyes were not seriously considered regarding their environmental impacts, even the chemical compositions of dyes were unknown. The textile industry is the largest consumer of dyestuffs. Reactive dyes cause major problems with respect to color [1]. Reactive dye in the waste stream can be detected by human eyes, if present, at approximately $0.005 \mathrm{mg} \cdot \mathrm{L}^{-1}$; therefore, wastewater exceeding limits could not be allowed for aesthetic reasons [2]. During the coloration process, a large portion of the synthetic dye does not bind and it is lost to the waste stream; therefore, the effluent from textile industries carries a large amount of dyes and other additives that cause water contamination [3]. Dyes can have adverse and toxic effects to humans, such as skin irritation and cancer [4]. Untreated dyes cause biological and chemical changes in aquatic system by reducing light penetration, thereby affecting photosynthetic activities [5]. Therefore, there is a need to treat the effluent before discharge and comply with the environmental regulations.

The conventional treatment methods for wastewater include biological, chemical and physical methods. The main drawbacks of biological treatment are low biodegradability, less flexibility in design and operation, larger land area requirements and longer times required for decolorization-fermentation processes [6-8]. To address these drawbacks, some cost-effective treatment technologies can be adopted that may use natural resource materials.

The adsorption process is one of the most effective methods for the removal of dyes from wastewater [9]. The process of adsorption has an advantage over the other methods due to its cost-effectiveness and sludge free clean operation [10]. Adsorbents that are commercially available, e.g., commercially activated carbon, are very effective but expensive [11,12]. Therefore, research is currently focused on adsorbents that remove dyes from wastewater at a low cost. An adsorbent can be considered low cost if it requires little processing is abundant in nature, or is a byproduct or waste material from another industry [13]. Therefore, the natural adsorbents have gained much attention for the adsorption of various pollutants from an aqueous medium [14].

In the last decade, bentonite clay has been successfully applied for the adsorption of dyes and metal ions $[15,16]$. Bentonite clay has been considered as a potential adsorbent for the removal of pollutants from water. In the present research study, the adsorption capacity of bentonite clay was investigated for removing Reactive Black 5 (RB5) dye from an aqueous solution.

\section{Materials and Methods}

\subsection{Adsorbent Preparation}

Bentonite clay was used as an adsorbent and obtained from the province of Riyadh (Saudi Arabia). Before the adsorption process, the clay was grounded and sieved to acquire the variable particle sizes. 


\subsection{Surface Characterization}

Surface characterization of bentonite clay was performed using Fourier Transform Infrared Spectroscopy (FTIR). FTIR spectra of the bentonite clay were performed in the transmission mode at room temperature using the $\mathrm{KBr}$ pellet method.

X-ray Powder Diffraction (XRD) was performed to analyze the effect of RB5 on the structure of bentonite clay. Homogeneous alloys were prepared by casting and sintering at temperature of $298 \mathrm{~K}$. Afterwards, one gram bentonite clay sample was packed in an aluminum sample holder and analyzed with an automated $\mathrm{X}$-ray diffraction instrument with a $\mathrm{Cu}-\mathrm{K} \alpha$ radiations $(\lambda=1.5418 \mathrm{~nm})$ source operating at voltage of $40 \mathrm{kV}\left(40 \mathrm{~mA}\right.$ current) in the $2 \theta$ range from $20^{\circ}-80^{\circ}$ in steps of $0.02^{\circ}$ at a rate of $2.6^{\circ}$ per minute.

\subsection{Adsorbate Solution Preparation}

Analytical (Merck) grade RB5 was used as an adsorbate. The chemical formula of RB5 is $\mathrm{C}_{26} \mathrm{H}_{21} \mathrm{~N}_{5} \mathrm{Na}_{4} \mathrm{O}_{19} \mathrm{~S}_{6}$, and its molecular weight is $991.82 \mathrm{~g} / \mathrm{mol}$. Stock solution of $1000 \mathrm{mg} \cdot \mathrm{L}^{-1}$ (1000 ppm) was prepared by diluting it with deionized water.

\subsection{Batch Experimentation}

In batch adsorption experiments, the adsorbent dosage of $0.05 \mathrm{~g}$ was added to $100 \mathrm{~mL}$ conical flasks having $50 \mathrm{~mL}$ synthetic RB5 dye solution of known concentration $\left(50 \mathrm{mg} \cdot \mathrm{L}^{-1}\right)$. The flasks were placed in a shaking incubator, with fuzzy control system, under the set conditions of contact time (60 min), shaking speed $(100 \mathrm{rpm})$ and temperature $\left(30^{\circ} \mathrm{C}\right)$ (WIS-20, Korea). Aforesaid conditions of batch experiments were kept constant during the optimization of various parameters effects on the RB5 dye adsorption capacity of bentonite clay. The effects of agitation were also assessed in the range of 100 to $240 \mathrm{rpm}$ using orbital shaker. The effects of temperature, $\mathrm{pH}$, contact time, initial dye concentration and particle size, on the adsorption capacity of bentonite clay were tested in the range of $30-50{ }^{\circ} \mathrm{C}$, 3-10, 40-300 $\mathrm{min}, 25-175 \mathrm{mg} \cdot \mathrm{L}^{-1}$ and 125-250 $\mu \mathrm{m}$, respectively. After the batch experiment, the filtrate was analyzed at $598 \mathrm{~nm}$ wavelength for RB5 using T80+UV/VIS spectrophotometer.

The amount of RB5 dye adsorbed and the adsorption efficiency ( $\%$ \%) of the bentonite clay was calculated using Equations (1) and (2).

$$
\begin{gathered}
q_{e}=\left(\frac{C_{0}-C_{f}}{m}\right) V \\
S(\%)=\left(\frac{C_{0}-C_{f}}{m}\right) V \times \frac{100}{C_{0}}
\end{gathered}
$$

where $C_{o}$ and $C_{f}$ are the initial and final concentrations $\left(\mathrm{mg} \cdot \mathrm{L}^{-1}\right)$, respectively, $\mathrm{q}_{\mathrm{e}}$ is the equilibrium concentration of RB5 dye $\left(\mathrm{mg} \cdot \mathrm{g}^{-1}\right), V$ is the volume of the solution (L), and $m$ is the mass of adsorbent (g). 


\subsection{Equilibrium Adsorption Isotherm Models}

The adsorption isotherm describes how adsorbates interact with an adsorbent and is critical in optimizing the use of adsorbent. Adsorption equilibrium studies are conducted to correlate the adsorption capacity $\left(\mathrm{q}, \mathrm{mg} \cdot \mathrm{g}^{-1}\right)$ and residual adsorbate concentration $\left(\mathrm{Ce}, \mathrm{mg} \cdot \mathrm{L}^{-1}\right)$ in the liquid phase $[17,18]$. Because of the complex adsorption system in liquid phase, it was essential to apply various isotherm models, i.e., Langmuir [19], Freundlich [20], Dubinin-Radushkevich (D-R) [21], and Temkin [22], to find an accurate relationship between dye in the liquid and solid phase.

Langmuir model (Equation (3)) has been frequently applied for the removal of heavy metals and dyes [23,24]. The Langmuir isotherm model is used to establish the relationship in monolayer coverage of adsorbate molecules. The model assumes that homogeneous active sites exist at the surface of an adsorbent and that there are no interactions between two adsorbed species [19].

$$
\frac{1}{\mathrm{q}_{\mathrm{e}}}=\frac{1}{K_{L} \cdot q_{\max } C_{e}}+\frac{1}{q_{\max }}
$$

where $\mathrm{K}_{\mathrm{L}}$ is the Langmuir constant (intercept/slope), and $\mathrm{q}_{\max }$ is the maximum adsorption capacity $\left(\mathrm{mg} \cdot \mathrm{g}^{-1}\right)$ i.e., $1 /$ intercept; both are calculated from the plot $\frac{1}{\mathrm{q}_{\mathrm{e}}}$ vs. $\frac{1}{\mathrm{C}_{\mathrm{e}}}$. Moreover, $\mathrm{C}_{\mathrm{e}}\left(\mathrm{mg} \cdot \mathrm{L}^{-1}\right)$ is the equilibrium adsorbate concentration in solution, and $\mathrm{q}_{\mathrm{e}}\left(\mathrm{mg} \cdot \mathrm{g}^{-1}\right)$ is the equilibrium adsorbent capacity.

Further analysis of the Langmuir model can be performed using the dimensionless equilibrium parameter [25], which is also called the separation factor (Equation (4)) [26].

$$
\mathrm{R}_{\mathrm{L}}=\frac{1}{1+\mathrm{K}_{\mathrm{L}} \mathrm{C}_{0}}
$$

$\mathrm{R}_{\mathrm{L}}$ is the dimensionless constant that indicates the favorability of the adsorption process.

Harkin-Jura (H-J) isotherm model assumes the possibility of multilayer adsorption on the surface of adsorbent having a heterogeneous pore distribution [2]. Mathematically, this model can be expressed as in Equation (5).

$$
\frac{1}{q_{e}^{2}}=B / A-\left(\frac{1}{A}\right) \log C_{e}
$$

where $\mathrm{B}$ and $\mathrm{A}$ are $\mathrm{H}-\mathrm{J}$ constants obtained from plot $1 / \mathrm{qe}^{2}$ vs. $\log C_{e}$.

The heat of adsorption decreases in magnitude with increasing adsorption for most of the adsorption systems [6]. This behavior is well considered by the Freundlich isotherm, previously known as an empirical isotherm. The Freundlich isotherm also assumes the pollutant undergoes adsorption onto the heterogeneous adsorbent. For solute adsorption from solution, the Freundlich isotherm is described by Equation (6).

$$
q_{e}=K_{F} c_{e}{ }^{1 / n}
$$

where $\mathrm{K}_{\mathrm{f}}$ and $1 / n$ indicate the relative adsorption capacity and the heterogeneity factor, respectively.

The Temkin isotherm model postulates the following: (i) the heat of adsorption of the surface molecules decreases linearly rather than logarithmically with coverage [27]; (ii) the adsorption process is characterized by a uniform distribution of binding energies at the adsorbent surface [28]; and (iii) this model covers the adsorbate-adsorbent interaction [22]. The nonlinear form of Temkin model is given by Equation (7). 


$$
\mathrm{q}_{\mathrm{e}}=\frac{\mathrm{RT}}{\mathrm{b}_{\mathrm{T}}} \ln \left(\mathrm{A}_{\mathrm{T}} \mathrm{C}_{\mathrm{e}}\right)
$$

This equation can be linearized as Equation (8):

$$
\mathrm{q}_{\mathrm{e}}=\mathrm{B}_{\mathrm{T}} \ln \mathrm{A}_{\mathrm{T}}+\mathrm{B}_{\mathrm{T}} \ln \mathrm{C}_{\mathrm{e}}
$$

where $\mathrm{B}_{\mathrm{T}}=\frac{\mathrm{RT}}{\mathrm{b}_{\mathrm{T}}}$, and $\mathrm{T}$ and $\mathrm{R}$ are absolute temperature $(\mathrm{k})$ and the universal gas constant $\left(8.314 \mathrm{~J} \cdot \mathrm{mol}^{-1} \cdot \mathrm{K}^{-1}\right)$, respectively.

The Halsey isotherm (Equation (9)) is suitable for multilayer adsorption; the adsorbent is heterogeneous in nature if the Halsey isotherm well fits the equilibrium data [15]. The Halsey isotherm is generally expressed as:

$$
\mathrm{q}_{\mathrm{e}}=\exp \left(\frac{\ln \mathrm{K}_{\mathrm{H}}-\ln \mathrm{C}_{\mathrm{e}}}{\mathrm{n}_{\mathrm{H}}}\right)
$$

Equation (9) can be written in linearized form as Equation (10):

$$
\operatorname{lnq}_{\mathrm{e}}=\frac{1}{\mathrm{n}_{\mathrm{H}}} \ln \mathrm{K}_{\mathrm{H}}-\frac{1}{\mathrm{n}_{\mathrm{H}}} \ln \mathrm{C}_{\mathrm{e}}
$$

where $\mathrm{kH}$ and $\mathrm{n}$ are Halsey's isotherm constants and are calculated from the slope and intercept of the plot lnqe $v s$. $\ln \mathrm{C}_{\mathrm{e}}$.

The D-R isotherm (Equation (11)) was also used to analyze the equilibrium data [4]. This model was neither based on the homogenous surface assumption nor the constant potential of adsorption.

$$
\ln q_{e}=\ln q_{D R}-\beta \varepsilon^{2}
$$

where $q_{D R}$ is the theoretical monolayer sorption capacity $\left(\mathrm{mg} \cdot \mathrm{g}^{-1}\right)$, and $\beta$ is the constant of adsorption energy $\left(\mathrm{mol}^{2} \cdot \mathrm{KJ}^{-2}\right)$.

\subsection{Adsorption Kinetics}

Experiments regarding the adsorption kinetics were performed to determine the rate of adsorption as adsorption is a time dependent process. It is necessary to know the rate of adsorption for the design and evaluation of a treatment system. Kinetic experiments were performed by varying the initial adsorbate concentration, i.e., 25,75 , and $100 \mathrm{mg} \cdot \mathrm{L}^{-1}$ over variable time steps.

\subsection{Statistical Analysis}

All measurements reported in the present study are average values of multiple (at least three) independent measurements. Statistical analysis was performed by computer software Statistica Statsoft 10 (Dell Software, Round Rock, TX, USA). All data were subjected to one-way analysis of variance (ANOVA), and differences were considered significant at $p=0.01$. 


\section{Results and discussions}

\subsection{Surface Characterization of Bentonite Clay}

Surface characterization of bentonite clay was performed before adsorption using FTIR analysis (Figure 1a). FTIR spectra were recorded in the range of 400-4000 $\mathrm{nm}$. Surface chemistry is important especially when chemisorption is dominant in the adsorption system. The FTIR peak at $3416 \mathrm{~cm}^{-1}$ is linked to the stretching vibration of $\mathrm{H}_{2} \mathrm{O}$; the peak at $1628 \mathrm{~nm}$ corresponds to the bending vibration of $\mathrm{H}_{2} \mathrm{O}$; the peak at $1118 \mathrm{~nm}$ corresponds to the stretching vibration of $\mathrm{SiO}$; the peak at $1026 \mathrm{~cm}^{-1}$ denotes siloxane ( $\mathrm{Si}-\mathrm{O}-\mathrm{Si}$ ) stretching; the peak at $913 \mathrm{~nm}$ denotes the bending vibration of $\mathrm{AlAlOH}$; and $841 \mathrm{~nm}$ to the bending vibration of $\mathrm{AlMgOH}[26,29-31]$.
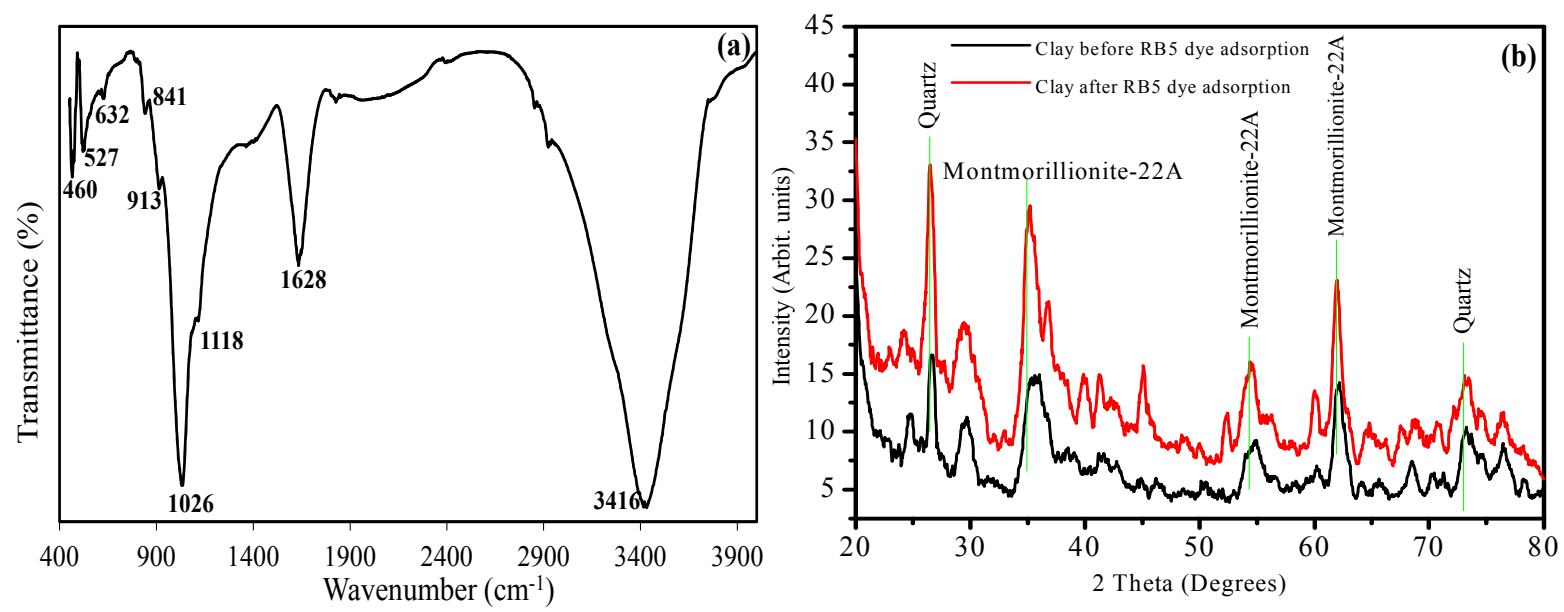

Figure 1. (a) Fourier Transform Infrared Spectroscopy (FTIR) analysis of the surface of bentonite clay; and (b) comparison of the X-ray Powder Diffraction (XRD) results.

Moreover, FTIR peaks at $632 \mathrm{~nm}$ are associated to the Al-O connection that was in a tetrahedral coordination with aluminum cations [32]. The FTIR peaks at $527 \mathrm{~nm}$ and $460 \mathrm{~nm}$ are associated to $\mathrm{Al}-\mathrm{O}-\mathrm{Si}$ and $\mathrm{Si}-\mathrm{O}-\mathrm{Si}$ bending vibrations, respectively [33,34]. Montmorillionite-22A is the main component of bentonite clay. Montmorillionite-22A and Quartz were found in the XRD results (Figure 1b).

The most dominant peak was of Quartz, while a significant amount of Montmorillionite-22A was also present. A clear peak shift was observed in the bentonite clay structure after the treatment of RB5 dye. All five peaks were shifted towards the right, i.e., the crystallinity of bentonite clay decreased after treatment. The peak of Montmorillionite-22A, which is at an angle of 35 degrees, was broadened after treatment, i.e., the crystallinity decreased. The same trend was followed by the remaining peaks of Montmorillionite-22A in the structure. The above observations provide evidence of the adsorption of RB5 on the bentonite clay.

\subsection{Effects of Different Reaction Parameters}

\subsubsection{Effects of the Shaking Speed on the Bentonite Clay Capacity for RB5}

The effects of shaking speed (rpm) on the adsorption capacity of bentonite were observed in the range of 100 to $240 \mathrm{rpm}$ (Figure 2a). A significantly high adsorption capacity (29-24 $\mathrm{mg} \cdot \mathrm{g}^{-1}, 58 \%$ ) 
was observed at 100 to $175 \mathrm{rpm}$, whereas a significantly $(p=0.01)$ low adsorption capacity was observed at 200 to $240 \mathrm{rpm}\left(9-10 \mathrm{mg} \cdot \mathrm{g}^{-1}, 20 \%\right)$. Therefore, $100 \mathrm{rpm}$ was selected as the optimum shaking speed for the other batch adsorption experiments in the current study.
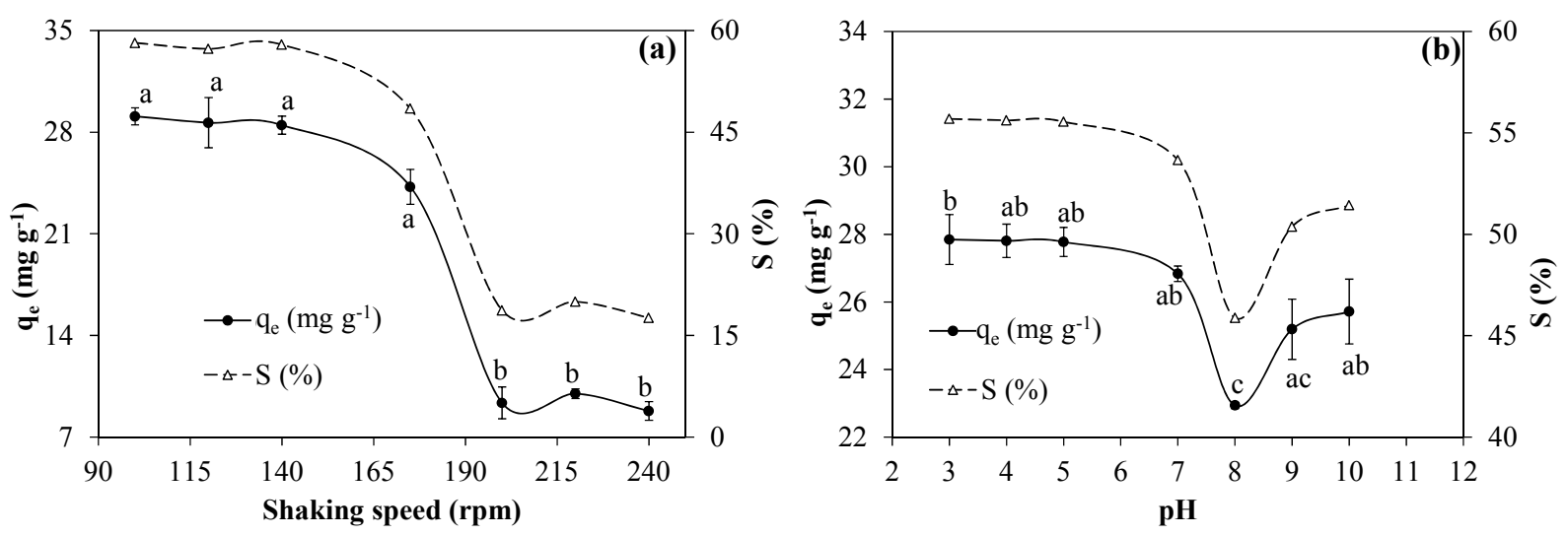

Figure 2. Effects of shaking speed (a) and $\mathrm{pH}$ (b) on the Reactive Black 5 (RB5) adsorption capacity of bentonite clay. Different letters on the error bars represent mean significant difference at $p=0.01$.

\subsubsection{Effects of $\mathrm{pH}$}

$\mathrm{pH}$ is an important parameter for the contaminant removal during the adsorption system. The degree of RB5 adsorption is primarily influenced by the surface charge on the bentonite clay, which is affected by the solution $\mathrm{pH}$. The effects of solution $\mathrm{pH}$ on $\mathrm{RB} 5$ adsorption were examined over the $\mathrm{pH}$ range of 3-10 (Figure 2b). RB5 adsorption onto bentonite clay was significantly ( $p=0.01$ ) lower at solution $\mathrm{pH} 8\left(22.94 \mathrm{mg} \cdot \mathrm{g}^{-1}, 45.88 \%\right)$ than at $\mathrm{pH} 10\left(26.91 \mathrm{mg} \cdot \mathrm{g}^{-1}, 53 \%\right) \cdot \mathrm{pH} 10$ was maintained for the rest of the batch adsorption experiments.

\subsubsection{Effects of Temperature}

The equilibrium adsorption capacity of bentonite clay were significantly $(p=0.01)$ lower $\left(23.86 \mathrm{mg} \cdot \mathrm{g}^{-1}, 48 \%\right)$ at the temperature of $40{ }^{\circ} \mathrm{C}$ than that at $30{ }^{\circ} \mathrm{C}\left(25.57 \mathrm{mg} \cdot \mathrm{g}^{-1}, 51 \%\right)$ and $50{ }^{\circ} \mathrm{C}$ $\left(27.75 \mathrm{mg} \cdot \mathrm{g}^{-1}, 58 \%\right)$, as shown in Figure 3 . The equilibrium adsorption capacity of RB5 decreased from 25.57 to $23.86 \mathrm{mg} \cdot \mathrm{g}^{-1}$ when the temperature was increased from $30{ }^{\circ} \mathrm{C}$ to $40{ }^{\circ} \mathrm{C}$. This result indicates that an exothermic reaction is controlling the adsorption of RB5 onto bentonite clay in this temperature range. However, increasing RB5 adsorption onto bentonite clay was observed in the range of $40{ }^{\circ} \mathrm{C}$ to $50{ }^{\circ} \mathrm{C}$, reflecting the endothermic nature of bentonite clay (Figure 3 ).

It can be attributed to high surface coverage, creation of active and reactive sites and expansion at higher temperature. In general, the solubility of a RB5 may be increased if the temperature increases. Thus, the amount of RB5 on the solid phase will decrease when approaching equilibration. The same phenomenon was observed in Bisphenol A adsorption on sediments [35]. 


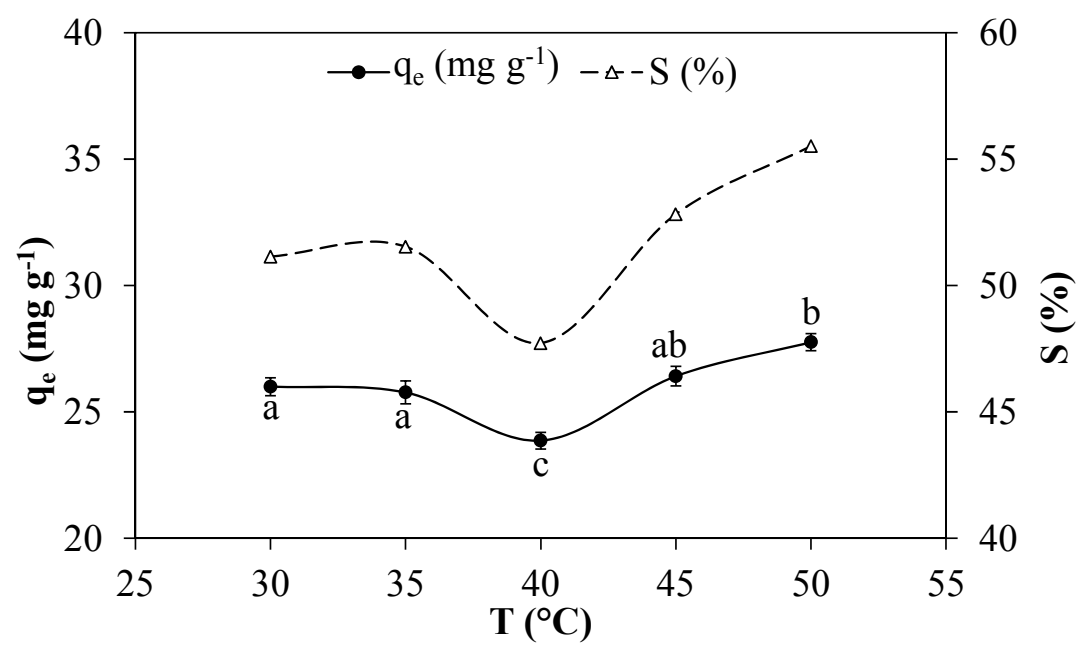

Figure 3. Effects of temperature on the RB5 adsorption capacity of bentonite clay. Different letters on the error bars represent mean significant difference at $p=0.01$.

\subsubsection{Effects of the Contact Time}

The data of RB5 adsorption on the bentonite clay showed that a contact time of 60 min was sufficient to achieve the equilibrium $\left(\mathrm{q}_{\mathrm{e}}=24 \mathrm{mg} \cdot \mathrm{g}^{-1}, 49 \%\right)$, as shown in Figure 4 . Moreover, the optimum contact time was chosen as $60 \mathrm{~min}$. Afterwards, the RB5 adsorption was not increased, even when experiment was run for $5 \mathrm{~h}$.

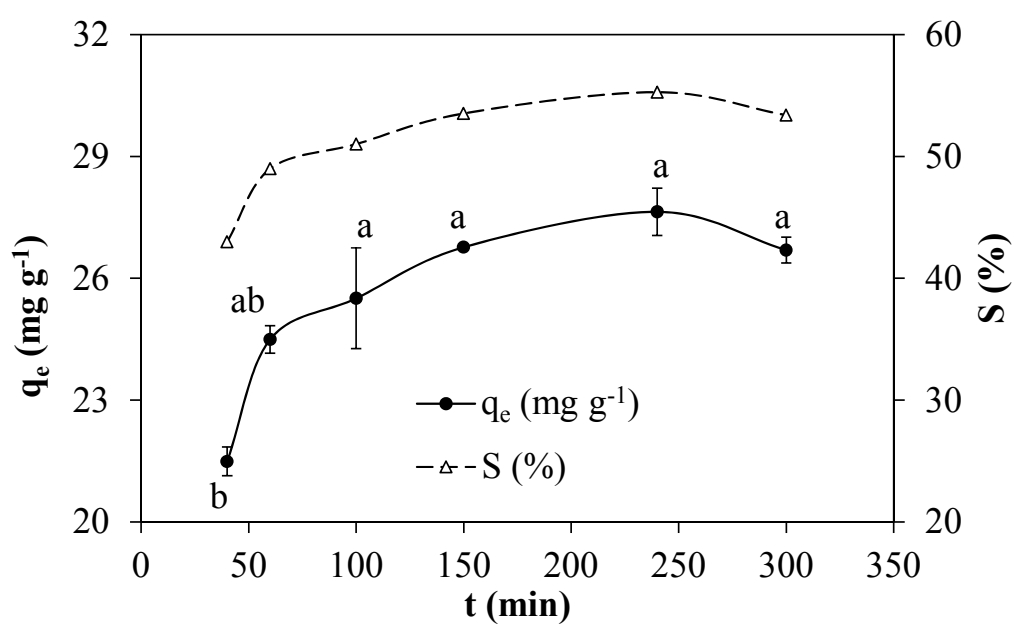

Figure 4. Effects of contact time on the RB5 adsorption capacity of bentonite clay. Different letters on the error bars represent mean significant difference at $p=0.01$.

Moreover, the initial rate of RB5 adsorption was high and decreased gradually over time. This response is probably due to the abundant availability of the active sites on the adsorbent surface during the first $60 \mathrm{~min}$. Afterwards, the repulsive forces between the RB5 dye molecules on the adsorbent and in the bulk phases hinder the remaining empty active sites from being occupied [36,37]. 


\subsubsection{Effects of the Initial Adsorbate Concentration}

The initial RB5 concentration creates an important driving gradient force to overcome the mass transfer resistance to dyes between the solid and aqueous phases. The data showed that RB5 adsorption capacity of bentonite clay was increased from 13 to $38 \mathrm{mg} \cdot \mathrm{g}^{-1}$ with RB5 dye concentration increasing from 25 to $175 \mathrm{mg} \cdot \mathrm{L}^{-1}$ (Figure $5 \mathrm{a}$ ). This could be because of a high-mass transfer force. However, the RB5 percent removal decreased from 52 to 22 due to the saturation of binding sites onto the bentonite clay.
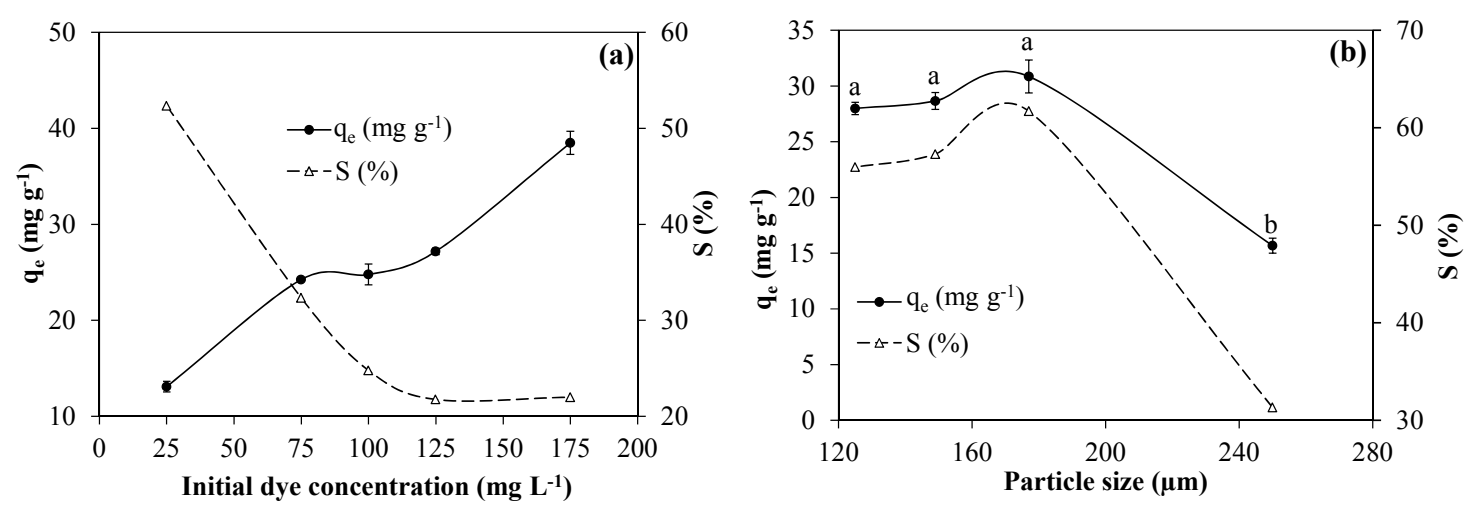

Figure 5. Effect of dye concentration (a) and particle size (b) on the RB5 adsorption capacity of bentonite clay. Different letters on the error bars represent mean significant difference at $p=0.01$.

\subsubsection{Effects of the Particle Size}

The particle size of bentonite clay can affect its adsorption capacity for RB5 dye. The data reflected the significantly ( $p=0.01$ ) high RB5 adsorption $\left(28-31 \mathrm{mg} \cdot \mathrm{g}^{-1}\right.$ ) in the particle size range of 125 to $177 \mu \mathrm{m}$ compared to $16 \mathrm{mg} \cdot \mathrm{g}^{-1}$ at $250 \mu \mathrm{m}$ (Figure $5 \mathrm{~b}$ ), due to the larger surface area of bentonite in the aforesaid range. Moreover, smaller particles provide better accessibility of RB5 molecules into the pores.

\subsection{Adsorption Equilibrium Isotherms}

Different isotherm models including Langmuir, H-J, Freundlich, Temkin, Halsey, and D-R were applied, as described earlier, to correlate the adsorption capacity and residual adsorbate concentration.

\subsubsection{Langmuir Isotherm}

The coefficient of determination $\left(R^{2}\right)$ for the Langmuir isotherm was 0.9915 (Figure 6a), which reflects the suitability of this model in describing the adsorption data. Adsorption of any contaminant is considered favorable if the $\mathrm{R}_{\mathrm{L}}$ (Equation (4)) value follows $0<\mathrm{R}_{\mathrm{L}}<1$; otherwise, it is considered unfavorable $\left(\mathrm{R}_{\mathrm{L}}>1\right)$, linear $\left(\mathrm{R}_{\mathrm{L}}=1\right)$ and irreversible $\left(\mathrm{R}_{\mathrm{L}}=0\right)$. In the current study, the measured $\mathrm{R}_{\mathrm{L}}$ value $(0.153)$ indicated the favorable adsorption of RB5 onto bentonite clay. 

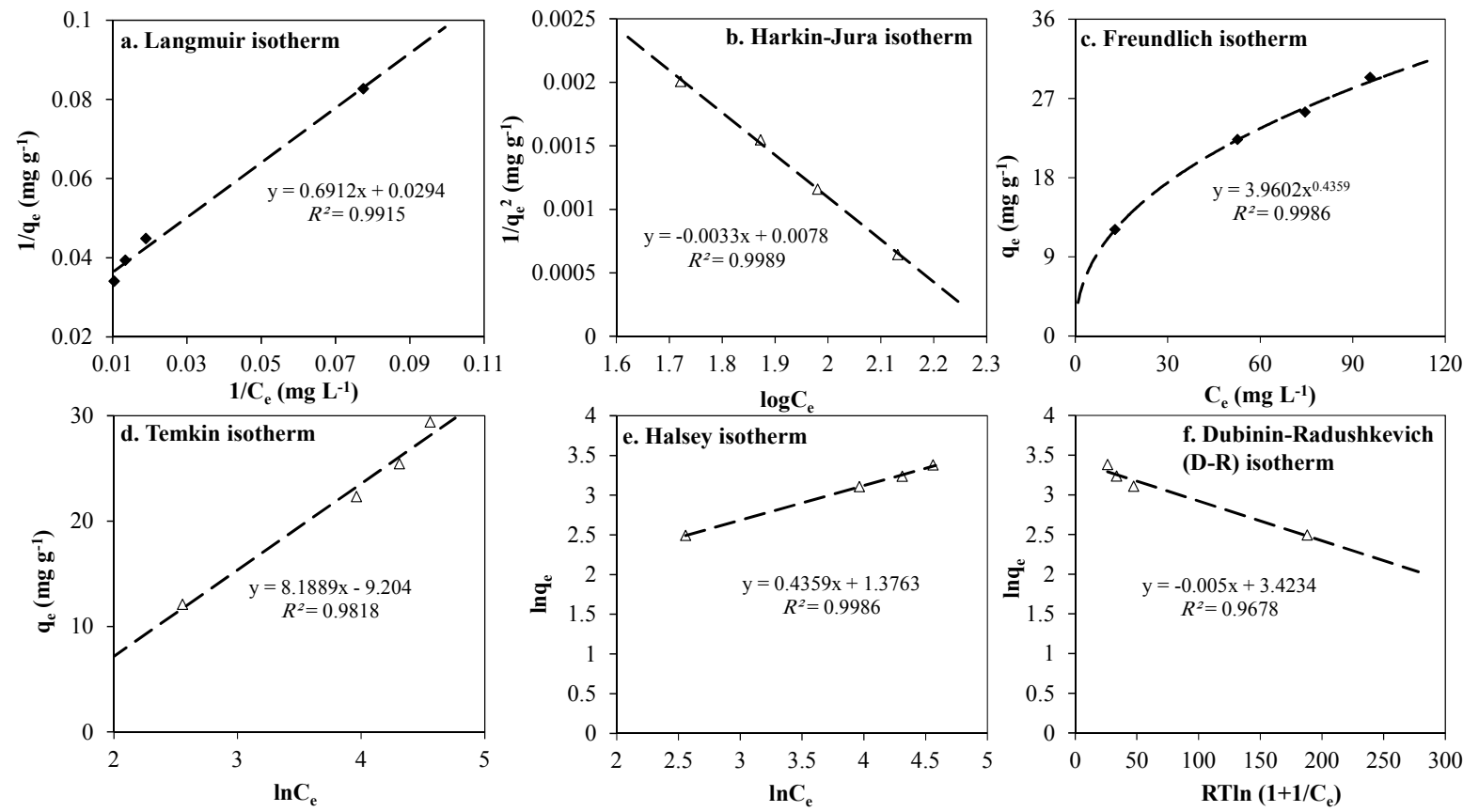

Figure 6. Plots and relevant parameters in different isotherms.

\subsubsection{Harkin-Jura (H-J) Isotherm}

Values of constants B and A of H-J isotherm model (Equation (5)) were obtained from plot 1/qe ${ }^{2} v s$. $\log C_{e}$ (Table 1, Figure 6b), this model showed a better fit to the adsorption data than the Langmuir, Freundlich, Halsey and Temkin isotherms models, with an $R^{2}$ value of 0.9989 .

Table 1. Adsorption isotherm constants.

\begin{tabular}{|c|c|c|c|}
\hline Isotherm & Parameter & Unit & Value \\
\hline \multirow{4}{*}{ Langmuir } & $q_{\exp }$ & $\mathrm{mg} \cdot \mathrm{g}^{-1}$ & 29.38 \\
\hline & $\mathrm{q}_{\max }$ & $\mathrm{mg} \cdot \mathrm{g}^{-1}$ & 34.01 \\
\hline & $\mathrm{K}_{\mathrm{ads}}$ & $\mathrm{L} \cdot \mathrm{mg}^{-1}$ & 0.043 \\
\hline & \multicolumn{2}{|c|}{$R^{2}$} & 0.9915 \\
\hline \multirow{3}{*}{ Harkin-Jura } & $\mathrm{A}$ & $\mathrm{mg} \cdot \mathrm{g}^{-1}$ & 303 \\
\hline & \multicolumn{2}{|c|}{$B$} & 2.36 \\
\hline & \multicolumn{2}{|c|}{$R^{2}$} & 0.9989 \\
\hline \multirow{4}{*}{ Freundlich } & \multicolumn{2}{|c|}{$1 / n$} & 0.4359 \\
\hline & \multicolumn{2}{|c|}{$n$} & 2.294 \\
\hline & $\mathrm{KF}$ & $\left(\mathrm{L} \cdot \mathrm{g}^{-1}\right)$ & 28.91 \\
\hline & $\mathrm{R}^{2}$ & & 0.9986 \\
\hline \multirow{3}{*}{ Temkin } & $\mathrm{A}_{\mathrm{T}}$ & $\mathrm{L} \cdot \mathrm{mg}^{-1}$ & 3.08 \\
\hline & $\mathrm{b}_{\mathrm{T}}$ & $\mathrm{kJ} \cdot \mathrm{mol}^{-1}$ & 312.85 \\
\hline & $R^{2}$ & & 0.98182 \\
\hline
\end{tabular}


Table 1. Cont.

\begin{tabular}{|c|c|c|c|}
\hline Isotherm & Parameter & Unit & Value \\
\hline \multirow{4}{*}{ Halsey } & & & 28.91 \\
\hline & & & -2.29 \\
\hline & & & 23.51 \\
\hline & $R^{2}$ & & 0.9986 \\
\hline \multirow{4}{*}{$\begin{array}{c}\text { Dubinin- } \\
\text { Radushkevich }\end{array}$} & $\mathrm{q}_{\mathrm{DR}}$ & $\mathrm{mol} \cdot \mathrm{g}^{-1}$ & 30.67 \\
\hline & $\beta$ & $\left(\mathrm{mol} \cdot \mathrm{g}^{-1}\right)^{2}$ & 0.003 \\
\hline & $E$ & $\mathrm{~kJ} \cdot \mathrm{mol}^{-1}$ & 14.14 \\
\hline & $R^{2}$ & & 0.9678 \\
\hline
\end{tabular}

\subsubsection{Freundlich Isotherm}

As described in Equation (6), values of $\mathrm{K}_{\mathrm{f}}$ and $1 / n$ in Freundlich isotherm model were measured as $28.91 \mathrm{mg} \cdot \mathrm{g}^{-1}$ and $0.4359(n=2.294)$, respectively, as indicated in Table 1; the latter determines the intensity and feasibility of the adsorption process. The values of the constants can be calculated from the plot of $\mathrm{q}_{\mathrm{e}} v s . \mathrm{c}_{\mathrm{e}}$. RB5 adsorption onto bentonite clay is considered to be favourable because the Freundlich exponent values of $1 / n$ (or $n$ ) were less than 1 (or in the range 2-10) [16,17,20,38]. Generally, the value of $1 / n$ less than 1 and the value of $n$ in the range of 2-10 indicates good, 1-2 moderately difficult and below 1 poor adsorption characteristics. Moreover, the coefficient of determination in the Freundlich isotherm model for bentonite clay is 0.9986 , which is higher than that for the Langmuir isotherm (Figure 6c, Table 1). This result indicates that the equilibrium data are fitted well to the Freundlich isotherm model.

\subsubsection{Temkin Isotherm}

As described in Equations (7) and (8), $\mathrm{A}_{\mathrm{T}}\left(3.08 \mathrm{~L} \cdot \mathrm{g}^{-1}\right)$ is the equilibrium binding constant, which indicates the maximum bonding energy; $\mathrm{b}_{\mathrm{T}}(312.85 \mathrm{KJ} / \mathrm{mol})$ is the constant related to the heat of adsorption, these constants are calculated from the plot $\mathrm{q}_{\mathrm{e}} v s . \ln \mathrm{C}_{\mathrm{e}}$ and tabulated in Table 1 . However, the Temkin equation is good for predicting the equilibrium in the gas phase (when arrangement in a tightly packed structure with the same orientation is not required); conversely, the liquid-phase adsorption isotherms (complex adsorption systems) are usually not suitable to be represented [15]. Based on the coefficient of determination $\left(R^{2}, 0.9818\right.$, Figure $\left.6 \mathrm{~d}\right)$, it is concluded that this model does not fit well to the equilibrium data compared to the Langmuir, Freundlich, Harkin-Jura and Halsey isotherm models.

\subsubsection{Halsey Isotherm}

Figure 6e reflected the relatively better agreement to the adsorption data with $R^{2}=0.9986$ than the Langmuir isotherm; this result confirmed the heterogeneous nature of the bentonite clay (Figure 6e, Table 1). Moreover, the closeness of the theoretical $\left(28.91 \mathrm{mg} \cdot \mathrm{g}^{-1}\right)$ and experimental $\left(29.38 \mathrm{mg} \cdot \mathrm{g}^{-1}\right)$ results also confirmed the good representation of the equilibrium data using this model. 


\subsubsection{Dubinin-Radushkevich (D-R) isotherm}

Values of $q_{D R}$ and $\beta$ (Equation (11)) were calculated as $30.67 \mathrm{mg} \cdot \mathrm{g}^{-1}$ and $0.0025 \mathrm{~mol}^{2} \cdot \mathrm{kJ}^{-2}$, respectively. The coefficient of determination $\left(R^{2}, 0.9678\right.$, Figure $\left.6 \mathrm{f}\right)$ reflected a poor fit to the experimental equilibrium data compared to the other models used at constant temperature of $35^{\circ} \mathrm{C}$. $\varepsilon$ is the Polanyi potential, which is calculated using Equation (12).

$$
\varepsilon=R T \ln \left[1+\frac{1}{C_{e}}\right]
$$

However, this model is usually applied to determine the mean free energy of adsorption $(E)$. An adsorption process is called physical if the value of $E$ is less than $8 \mathrm{KJ} \cdot \mathrm{mol}^{-1}$, whereas it is called chemical if the $E$ values are between 8 and $16 \mathrm{KJ} \cdot \mathrm{mol}^{-1}[2,3]$.

$$
E=\frac{1}{\sqrt{2 \beta}}
$$

In the present study, the $E$ value in the ion exchange mechanism was $14.59 \mathrm{KJ} \cdot \mathrm{mol}^{-1}$, which reflected the chemisorption of RB5 onto the bentonite clay.

\subsection{Adsorption Kinetics}

Kinetics is an important consideration in assessing the adsorption potential of adsorbent. The effects of contact time on the RB5 adsorption capacity of bentonite clay are given in Figure 7. Adsorption reaction is based on the whole adsorption process without consideration of the actual mechanism of pollutant transport because analysis of the adsorption rates is sufficient from a system design viewpoint and for practical operation.

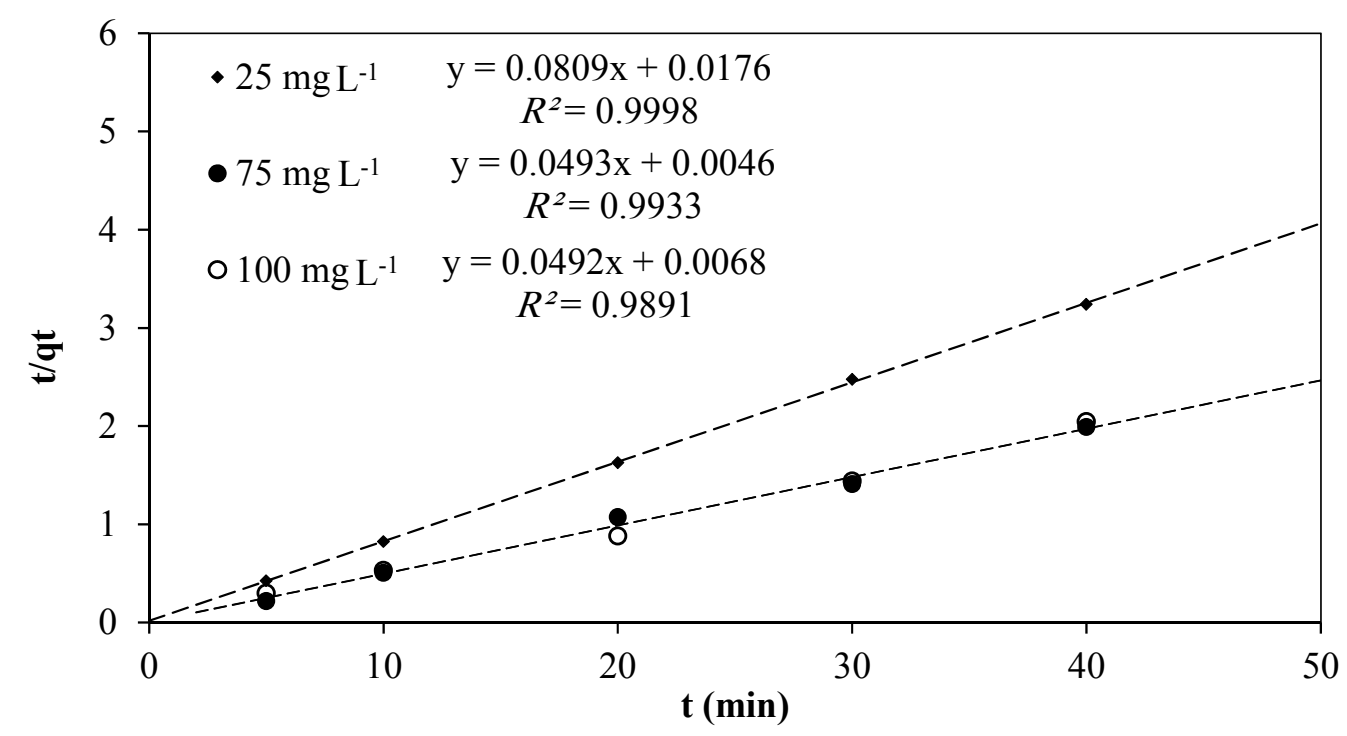

Figure 7. Pseudo-second order kinetic plots at different initial solution concentration $\left(25,75\right.$, and $\left.100 \mathrm{mg} \cdot \mathrm{L}^{-1}\right)$ for RB5 adsorption onto bentonite clay.

The pseudo-second order model is given in Equation (14). 


$$
\frac{t}{q_{t}}=\frac{1}{k_{2} q_{e}^{2}}+\frac{1}{q_{e}} t
$$

where $\mathrm{K}_{2}\left(\mathrm{~g} \cdot \mathrm{mg}^{-1} \cdot \mathrm{min}^{-1}\right)$ is the pseudo-second order rate constant, and $\mathrm{qt}$ is the amount of RB5 adsorbed at time $\mathrm{t}(\mathrm{min})$, which was calculated from the slope and intercept of the plot $\mathrm{t} / \mathrm{q}_{\mathrm{t}}$ versus $\mathrm{t}$. Based on the coefficient of determination, linear relationships were observed at 25,75 and $100 \mathrm{mg} \cdot \mathrm{L}^{-1}$ (Figure 7). The pseudo-first order and pseudo-second order reaction models were used to study the adsorption kinetics of RB5 dye onto bentonite clay. Only the pseudo-second order model showed an excellent fit to the adsorption data (Figure 7), which indicated that chemisorption is the rate limiting step. The experimental and calculated adsorption capacities are very close, confirming the application and validation of this model in the description of adsorption data (Table 2).

Table 2. Constants of the pseudo-second order reaction models.

\begin{tabular}{|c|c|c|c|c|c|}
\hline \multirow{2}{*}{$\begin{array}{l}\text { Initial RB5 Dye } \\
\text { Conc. }\left(\mathrm{mg} \cdot \mathrm{L}^{-1}\right)\end{array}$} & \multirow[b]{2}{*}{$q_{\text {e exp }}\left(m g \cdot g^{-1}\right)$} & \multicolumn{4}{|c|}{ Pseudo-Second Order } \\
\hline & & $K_{2}\left(g \cdot \mathrm{mg}^{-1} \cdot \mathrm{min}^{-1}\right)$ & $\begin{array}{c}q_{e \text { cal }} \\
\left(\mathrm{mg} \cdot \mathrm{g}^{-1}\right)\end{array}$ & $H\left(\mathrm{mg} \cdot \mathrm{g}^{-1} \cdot \min ^{-1}\right)$ & $\mathbf{R}^{2}$ \\
\hline 25 & 13.07 & 0.3719 & 12.36 & 56.81 & 0.9998 \\
\hline 75 & 27.18 & 0.5284 & 20.28 & 147.06 & 0.9933 \\
\hline 100 & 22.71 & 0.3560 & 20.33 & 147.06 & 0.9891 \\
\hline
\end{tabular}

\subsection{Thermodynamic Study}

Thermodynamics parameters were estimated to check the temperature effects on the RB5 adsorption capacity of bentonite clay. The distribution coefficient $\mathrm{K}_{\mathrm{d}}$ was calculated from Equation (15)

$$
K_{d}=\frac{q_{e}}{C_{e}}
$$

where $\mathrm{q}_{\mathrm{e}}$ is the solid phase concentration $\left(\mathrm{mg} \cdot \mathrm{g}^{-1}\right)$, and $\mathrm{C}_{\mathrm{e}}$ is the liquid phase concentration $\left(\mathrm{mg} \cdot \mathrm{L}^{-1}\right)$ at equilibrium. Changes in the standard enthalpy, $\Delta \mathrm{H}\left(\mathrm{kJ} \cdot \mathrm{mol}^{-1}\right)$ and entropy $\Delta \mathrm{S}\left(\mathrm{kJ} \cdot \mathrm{mol}^{-1}\right)$ were calculated from the Van't Hoff plot via Equation (16):

$$
\ln K_{d}=\frac{\Delta S}{R}+\frac{\Delta H}{R T}
$$

where $\mathrm{R}$ is the universal gas constant $\left(8.314 \mathrm{~J} \cdot \mathrm{mol}^{-1} \cdot \mathrm{K}^{-1}\right)$, and $\mathrm{T}$ is the temperature $(\mathrm{K})$. The values of $\Delta \mathrm{H}$ in the temperature ranges of 303-313 K (T1) and 313-323 K (T2) were -0.00056 and 0.0014 , respectively, reflecting the exothermic and endothermic nature, respectively, during the RB5 adsorption onto bentonite clay (Table 3). The values of $\Delta \mathrm{S}$ in the temperature ranges of $303-313 \mathrm{~K}$ (T1) and $313-323 \mathrm{~K}$ (T2) were observed as 0.0011 and -0.002 , respectively, which revealed the increased and decreased randomness in the $\mathrm{T} 1$ and $\mathrm{T} 2$ temperature ranges, respectively, at the solid-liquid interface during the RB5 adsorption onto bentonite clay (Table 3). The $\Delta \mathrm{G}$ (Gibbs free energy change, $\mathrm{kJ} \cdot \mathrm{mol}^{-1}$ ) values were obtained from Equation (17):

$$
\Delta \mathrm{G}=\Delta \mathrm{H}-\mathrm{T} \Delta \mathrm{S}
$$


Table 3. Thermodynamics parameters of RB5 dye adsorption onto bentonite clay.

\begin{tabular}{|c|c|c|c|c|c|c|c|}
\hline & \multirow{2}{*}{$\Delta \mathbf{H} /\left(\mathbf{k J} \cdot \mathrm{mol}^{-1}\right)$} & \multirow{2}{*}{$\Delta \mathrm{S} /\left(\mathbf{k J} \cdot \mathrm{mol}^{-1}\right)$} & \multicolumn{5}{|c|}{$\Delta \mathrm{G} /\left(\mathrm{kJ} \cdot \mathrm{mol}^{-1}\right)$} \\
\hline & & & $303 \mathrm{~K}$ & $308 \mathrm{~K}$ & $313 \mathrm{~K}$ & $318 \mathrm{~K}$ & $323 \mathrm{~K}$ \\
\hline $\mathrm{T} 1$ & -0.0006 & 0.0011 & -0.335 & -0.341 & -0.346 & & \\
\hline $\mathrm{T} 2$ & 0.0014 & -0.002 & & & 0.64 & 0.65 & 0.66 \\
\hline
\end{tabular}

The negative and positive values of $\Delta \mathrm{G}$ in the $\mathrm{T} 1$ and $\mathrm{T} 2$ temperature ranges confirmed that the adsorption of RB5 onto bentonite clay was a spontaneous and non-spontaneous process, respectively (Table 3).

\section{Conclusions}

In the current study, the adsorption potential of abundant and locally available raw bentonite was assessed against RB5 textile dye in the temperature range of 303-323 K. The characteristic parameters and mechanisms of adsorption of the present application were also investigated using isotherms and kinetic models. The optimized conditions for RB5 dye removal by bentonite were found: $\mathrm{pH}=10.0$, agitation rate $=100 \mathrm{rpm}$, equilibration time $=40 \mathrm{~min}, \mathrm{RB} 5$ dye concentration $=175 \mathrm{mg} \cdot \mathrm{L}^{-1}$ and particle size $=177 \mu \mathrm{m}$. Among the isotherms, the adsorption data reflected best fits in the following order based on the coefficient of determination: Harkin-Jura $>$ Freundlich and Halsey $>$ Langmuir $>$ Temkin $>$ Dubinin-Radushkevich. The adsorption data obeyed the pseudo-second order kinetic model, which suggested the chemisorption nature of the bentonite clay. Moreover, bentonite clay revealed the dual nature of exothermic and endothermic, spontaneous and non-spontaneous as well as increased and decreased randomness at the solid-liquid interface in $\mathrm{T} 1$ and $\mathrm{T} 2$ temperature ranges, respectively, based on the $\Delta \mathrm{H}, \Delta \mathrm{G}$ and $\Delta \mathrm{S}$ values.

\section{Acknowledgments}

This project was funded by the National Plan for Science, Technology and Innovation (MAARIFAH), King Abdulaziz City for Science and Technology, Kingdom of Saudi Arabia, Award Number (11-WAT1875-02).

\section{Author Contributions}

Muhammad Tahir Amin and Muhammad Shafiq conceived and designed the experiments; Muhammad Shafiq performed the experiments; Muhammad Tahir Amin and Abdulrahman Ali Alazba analyzed the data; Abdulrahman Ali Alazba contributed reagents/materials/analysis tools; Muhammad Tahir Amin, Abdulrahman Ali Alazba and Muhammad Shafiq wrote the paper. Muhammad Tahir Amin, Abdulrahman Ali Alazba and Muhammad Shafiq have read and approved the final manuscript.

\section{Conflicts of Interest}

The authors declare no conflict of interest. 


\section{References}

1. Mughal, M.J.; Saeed, R.; Naeem, M.; Ahmed, M.A.; Yasmien, A.; Siddiqui, Q.; Iqbal, M. Dye fixation and decolourization of vinyl sulphone reactive dyes by using dicyanidiamide fixer in the presence of ferric chloride. J. Saudi Chem. Soc. 2013, 17, 23-28.

2. Almeida, C.A.P.; Debacher, N.A.; Downs, A.J.; Cottet, L.; Mello, C.A.D. Removal of methylene blue from colored effluents by adsorption on montmorillonite clay. J. Colloid Interface Sci. 2009, 332, 46-53.

3. Babu, B.R.; Parande, A.K.; Kumar, T.P. Cotton Textile Processing: Waste Generation and Effluent Treatment. J. Cotton Sci. 2007, 11, 141-153.

4. Rai, H.S.; Bhattacharyya, M.S.; Singh, J.; Bansal, T.K.; Vats, P.; Banerjee, U.C. Removal of Dyes from the Effluent of Textile and Dyestuff Manufacturing Industry: A Review of Emerging Techniques With Reference to Biological Treatment. Crit. Rev. Environ. Sci. Technol. 2005, 35, 219-238.

5. Reddy, M.C.S.; Sivaramakrishna, L.; Reddy, A.V. The use of an agricultural waste material, Jujuba seeds for the removal of anionic dye (Congo red) from aqueous medium. J. Hazard. Mater. 2012, 203-204, 118-127.

6. Bhattacharyya, K. Adsorption characteristics of the dye, Brilliant Green, on Neem leaf powder. Dyes Pigment. 2003, 57, 211-222.

7. Crini, G. Non-conventional low-cost adsorbents for dye removal: A review. Bioresour. Technol. 2006, 97, 1061-1085.

8. Robinson, T.; McMullan, G.; Marchant, R.; Nigam, P. Remediation of dyes in textile effluent: A critical review on current treatment technologies with a proposed alternative. Bioresour. Technol. 2001, 77, 247-255.

9. Suteu, D.; Biliuta, G.; Rusu, L.; Coseri, S.; Nacu, G. Cellulose Cellets as new type of Adsorbent for the removal of Dyes from aqueous media. Environ. Eng. Manag. J. 2015, 14, 525-532.

10. Gupta, V.K.; Suhas. Application of low-cost adsorbents for dye removal-A review. J. Environ. Manag. 2009, 90, 2313-2342.

11. Etim, U.J.; Umoren, S.A.; Eduok, U.M. Coconut coir dust as a low cost adsorbent for the removal of cationic dye from aqueous solution. J. Saudi Chem. Soc. 2012, doi:10.1016/j.jscs.2012.09.014.

12. Kanawade, S.M.; Gaikwad, R.W. Removal of Methylene Blue from Effluent by Using Activated Carbon and Water Hyacinth as Adsorbent. Int. J. Chem. Eng. Appl. 2011, 2, 317-319.

13. Khan, N.A.; Ibrahim, S.; Subramaniam, P. Elimination of heavy metals from wastewater using agricultural wastes as adsorbents. Malays. J. Sci. 2004, 23, 43.

14. Parmar, M.; Thakur, L.S. Heavy metal Cu, Ni and Zn: Toxicity, health hazards and their removal techniques by low cost adsorbents: A short overview. Int. J. Plant Anim. Environ. Sci. 2013, 3, 143-157.

15. Tahir, H.; Hammed, U.; Sultan, M.; Jahanzeb, Q. Batch adsorption technique for the removal of malachite green and fast green dyes by using montmorillonite clay as adsorbent. Afr. J. Biotechnol. 2010, 9, 8206-8214.

16. Tahir, S.S.; Rauf, N. Removal of a cationic dye from aqueous solutions by adsorption onto bentonite clay. Chemosphere 2006, 63, 1842-1848. 
17. Hameed, B.H.; Chin, L.H.; Rengaraj, S. Adsorption of 4-chlorophenol onto activated carbon prepared from rattan sawdust. Desalination 2008, 225, 185-198.

18. Rehman, M.S.; Kim, I.; Han, J.-I. Adsorption of methylene blue dye from aqueous solution by sugar extracted spent rice biomass. Carbohydr. Polym. 2012, 90, 1314-1322.

19. Langmuir, I. The adsorption of gases on plane surfaces of glass, mica and platinum. J. Am. Chem. Soc. 1918, 40, 1361-1403.

20. Freundlich, H.M.F. Over the adsorption in solution. J. Phys. Chem. 1906, 57, 385-471.

21. Nguyen, C.; Do, D.D. The Dubinin-Radushkevich equation and the underlying microscopic adsorption description. Carbon 2001, 39, 1327-1336.

22. Temkin, M.J.; Pyzhev, V. Kinetics of the Synthesis of Ammonia on Promoted Iron Catalysts. Acta Physicochim. 1940, 12, 217-222.

23. Garg, U.K.; Kaur, M.P.; Garg, V.K.; Sud, D. Removal of hexavalent chromium from aqueous solution by agricultural waste biomass. J. Hazard. Mater. 2007, 140, 60-68.

24. Yang, X.; Al-Duri, B. Kinetic modeling of liquid-phase adsorption of reactive dyes on activated carbon. J. Colloid Interface Sci. 2005, 287, 25-34.

25. Hall, K.R.; Eagleton, L.C.; Acrivos, A.; Vermeulen, T. Pore- and Solid-Diffusion Kinetics in Fixed-Bed Adsorption under Constant-Pattern Conditions. Ind. Eng. Chem. Fundam. 1966, 5, 212-223.

26. Boraa, M.; Gangulia, J.N.; Duttaa, D.K. Thermal and spectroscopic studies on the decomposition of [Ni\{di(2-aminoethyl)amine 2$]$ - and [Ni(2,20:60,200-terpyridine)2]-Montmorillonite intercalated composites. Thermochim. Acta 2000, 346, 169-175.

27. Aharoni, C.; Ungarish, M. Kinetics of activated chemisorption. Part 2.-Theoretical models. J. Chem. Soc. Faraday Trans. 1977, 73, 456-464.

28. Kumar, P.S.; Ramakrishnan, K.; Gayathri, R. Removal of Nickel (II) from Aqueous Solutions by Ceralite IR 120 Cationic Exchange Resins. J. Eng. Sci. Technol. 2010, 5, 232-243.

29. AlSawalha, M.; Novikova, L.; Roessner, F.; Bel'chinskaya, L. Acidity of different Jordanian Clays characterized by TPD-NH3 and MBOH Conversion. World Acad. Sci. Eng. Technol. 2011, 5, $7-29$.

30. Leite, I.F.; Soares, A.P.S.; Carvalho, L.H.; Raposo, C.M.O.; Malta, O.M.L.; Silva, S.M.L. Characterization of pristine and purified organobentonites. J. Therm. Anal. Calorim. 2009, 100, 563-569.

31. Madejová, J. FTIR techniques in clay mineral studies. Vib. Spectrosc. 2003, 31, 1-10.

32. Tomul, F.; Balci, S. Synthesis and Characterization of Al-Pillared Interlayered Bentonites. GU J. Sci. 2008, 21, 21-31.

33. Cótica, L.F.; Freitas, V.F.; Santos, I.A.; Barabach, M.; Anaissi, F.J.; Miyahara, R.Y.; Sarvezuk, P.W.C. Cobalt-modified Brazilian bentonites: Preparation, characterisation, and thermal stability. Appl. Clay Sci. 2011, 51, 187-191.

34. Shao, D.D.; Xu, D.; Wang, S.W.; Fang, Q.H.; Wang, W.S.; Dong, Y.H.; Wang, X.K. Modeling of radionickel sorption on MX-80 bentonite as a function of $\mathrm{pH}$ and ionic strength. Sci. China Ser. B Chem. 2008, 52, 362-371. 
35. Zeng, G.; Zhang, C.; Huang, G.; Yu, J.; Wang, Q.; Li, J.; Xi, B.; Liu, H. Adsorption behavior of bisphenol A on sediments in Xiangjiang River, Central-south China. Chemosphere 2006, 65, 1490-1499.

36. Kalavathy, M.H.; Miranda, L.R. Comparison of copper adsorption from aqueous solution using modified and unmodified Hevea brasiliensis saw dust. Desalination 2010, 255, 165-174.

37. Srivastava, V.C.; Mall, I.D.; Mishra, I.M. Characterization of mesoporous rice husk ash (RHA) and adsorption kinetics of metal ions from aqueous solution onto RHA. J. Hazard. Mater. 2006, 134, 257-267.

38. Ahmaruzzaman, M.; Gayatri, S.L. Activated Tea Waste as a Potential Low-Cost Adsorbent for the Removal of p-Nitrophenol from Wastewater. J. Chem. Eng. Data 2010, 55, 4614-4623.

(C) 2015 by the authors; licensee MDPI, Basel, Switzerland. This article is an open access article distributed under the terms and conditions of the Creative Commons Attribution license (http://creativecommons.org/licenses/by/4.0/). 